\title{
Identification and Validation of Synthetic Phenolic Antioxidants in Various Foods Commonly Consumed in Malaysia by HPLC
}

\author{
Chen Son Yue ${ }^{1,}$, Wai Lun Hong', Sheri-Ann Shu Wei Tan ${ }^{2}$, Khye Er Loh ${ }^{2}$, Yee Chuan Liew ${ }^{2}$, Rosemary \\ Elizabeth Yap ${ }^{2}$, Zi Yi Chong ${ }^{2}$, and Jiong Chen Chai ${ }^{2}$
}

${ }^{1}$ Department of Physical Science, Faculty of Applied Sciences, Tunku Abdul Rahman University College, 53300 Kuala Lumpur, Malaysia

${ }^{2}$ Department of Bioscience, Faculty of Applied Sciences, Tunku Abdul Rahman University College, 53300 Kuala Lumpur, Malaysia

\section{*Corresponding author: \\ email: csyue2013@gmail.com; yuecs@tarc.edu.my}

Received: August 2, 2018

Accepted: October 18, 2018

DOI: $10.22146 / \mathrm{ijc} .37782$

\begin{abstract}
This study was conducted in order to identify the presence of four synthetic phenolic antioxidants (SPAs): propyl gallate (PG), tert-butylhydroquinone (TBHQ), butylated hydroxyanisole (BHA), and butylated hydroxytoluene (BHT) in various food stuffs that are commonly consumed in Malaysia. The identification method was optimized and validated before it was applied to the analyses of eighty three food samples which include chewing gum, chili sauce, cereal-based snack food, noodles, potato snack, cereal breakfast, oat, biscuit, cookie, coffee, junk food, seaweed, nut, chocolate, apple juice, orange juice and blackcurrant juice. Twenty nine food samples contained SPAs either singly or in combination. The chromatography conditions such as elution method, flow rate and wavelength were optimized. Good linearity ranges (1-300 $\left.\mathrm{mg} \mathrm{L}^{-1}\right)$ were found for all the four phenolic antioxidants. RSD for repeatability and reproducibility ranged from 0.15-0.84\% for both precision analyses. LOD and LOQ ranged from 0.02-0.67 and 0.06-2.03 $\mathrm{mg} \mathrm{L}^{-1}$, respectively. Recoveries of the four SPAs ranged from 80.4 to $119.0 \%$ when selected food items spiked at 10, 50, and $100 \mathrm{mg} \mathrm{L}^{-1}$.
\end{abstract}

Keywords: synthetic phenolic antioxidant; Malaysian food; validation; HPLC

\section{- INTRODUCTION}

Antioxidants either natural or synthetic are usually added to food stuffs to prevent or to delay the lipid oxidation of fats, oils and lipid-containing food stuffs. Natural occurring antioxidants such as natural antioxidants, mainly polyphenols extracted from plants and fruits, and vitamins are relatively more expensive and less stable due to their low availability and shorter shelflife when compared to synthetic antioxidants [1]. Therefore, synthetic antioxidants are preferred because of their relatively cheaper price, longer shelf-life and easy availability. A few decades ago, the use of synthetic phenolic antioxidants (SPAs) such as propyl gallate (PG), tertiary butyl hydroquinone (TBHQ), butylated hydroxyanisole (BHA), and butylated hydroxytoluene (BHT) have been started. Regulatory bodies in the USA,
EU and other countries have set the permitted levels for these SPAs. In EU, the amount of SPA is limited to $0.01 \%$ (or $0.1 \mathrm{~g} \mathrm{~kg}^{-1}$ ) for each antioxidant used, and $0.02 \%$ for total amount if the antioxidants are used in combination [2]. The use of SPAs that is approved by official legislation in EU include PG, BHA and BHT, while, the use of TBHQ as food additive is not registered in EU even though it has been widely used for this purpose. However, the use of TBHQ is permitted in other countries such as the United States, Australia, New Zealand and Philippines [1]. The use and the types of SPAs that are permitted to be added to food stuffs could vary in different countries, but most of the countries have set the maximum permitted levels of 100$200 \mathrm{mg} \mathrm{kg}^{-1}$ for SPAs in food stuffs, either singly or in combination [3]. In Malaysia, antioxidants are categorized under the Tenth Schedule (Regulation 24, 
Table 1) in Food Regulations 1985 [4]. The addition of antioxidants in foods either singly or in combination is permitted in Malaysia. According to the regulations, any food that contains antioxidant(s), a statement as to its/their presence should be stated. The maximum limit for individual SPA in foods is set at $100 \mathrm{mg} \mathrm{kg}^{-1}$ for PG, $200 \mathrm{mg} \mathrm{kg}^{-1}$ for TBHQ, BHA and BHT, respectively. The total SPAs for any combination such as BHA and BHT or PG with any other SPAs should not be more than $200 \mathrm{mg} \mathrm{kg}^{-1}$ [4-5].

The effects of SPAs on consumer health are contradictory. Based on the studies on animal tissues, there are several reports of carcinogenic effects even at very low concentration levels of SPAs [6]. The use of BHA and $\mathrm{BHT}$ in high quantities and long-term use have been reported to have carcinogenic effects [7]. There is evidence that high diet doses of BHT may lead to the development of lung and liver cancer. Indeed, the presence of BHT may increase the effect of other carcinogenic compounds [8]. Both BHA and BHT can act as endocrine disruptors, and the long-term use may cause infertility and growth problems [9]. On the other hand, the use of SPAs in drugs, foods and cosmetics at the recommended levels are reported to have anticarcinogenic, anti-tumor and anti-mutagenic effects [1]. Besides acting as a preservative to inhibit lipid oxidation in food stuff, these phenolic compounds also have an antimicrobial effect especially towards Gram positive bacteria [9]. Consequently, the determination and understanding of the SPAs levels in food stuffs are necessary to ensure fulfilment of the legal requirements as well as a safety measure and quality control of the food self-life.

The determination of SPAs in foodstuffs and other products have been carried out by a number of researchers. For example, the determination of SPAs in essence perfume using high performance liquid chromatography (HPLC) with UV, photodiode array detector [3]. The determination of synthetic antioxidants and preservatives in edible vegetable oil by HPLC/TOFMS [10]. Gas chromatographic flow method for the preconcentration and simultaneous determination of antioxidant and preservative additives in fatty foods [11].
Simultaneous determination for five synthetic antioxidants in edible oil by GC-MS [12]. Application of a capillary electrophoresis method for simultaneous determination of preservatives in pharmaceutical formulations [13] and so on. To the best of our knowledge, there isn't any report on the determination of PG, TBHQ, BHA and BHT in various food stuffs that are commonly consumed in Malaysia other than fats and oil related food products [14]. Therefore, determination and quantification of SPAs in these food stuffs is crucial to ensure the safety and quality of these foods. Among the methods as mentioned above, HPLC is the method of choice due to its versatility, precision and adequate sensitivity [14]. Therefore, the objective of this work is to develop and validate a simple method through the modification and improvement of the existing reported methods to suit the determination of SPAs in various food stuffs other than fats and oil related food products.

\section{- EXPERIMENTAL SECTION}

\section{Materials}

All chemicals and solvents used were of analytical and chromatographic grade. Propyl gallate, PG (98\%), tertiary butylhydroquinone, TBHQ (97\%), butylated hydroxyanisole, BHA (96\%), and butylated hydroxytoluene, BHT (99.8\%) were obtained from Acros Organics (New Jersey, USA). HPLC grade methanol and acetonitrile were obtained from Merck (Darmstadt, Germany). Glacial acetic acid (> 99.7\%) was purchased from Thermo Fischer Scientific (Waltham, USA) while deionized water was produced from the Mili-Q system (Merck Millipore, USA).

\section{Instrumentation and Chromatographic Conditions}

The quantitative analysis of SPAs was conducted using a HPLC unit (Agilent Technologies, California, USA) that consisted of the Agilent 1260 Infinity Quaternary Pump, a 1260 Infinity Diode-Array Detector, a Agilent 1260 infinity standard autosampler injector with a loop of $10 \mu \mathrm{L}$ and a reversed phase Agilent ZORBAX Eclipse XDB $5 \mu \mathrm{m}$ C18 column (150 $\mathrm{mm} \times 4.6 \mathrm{~mm})$. A gradient elution consisting of ultrapure water and HPLC grade acetonitrile (ACN) 
varied from 40 to $100 \% \mathrm{ACN}$ over $10 \mathrm{~min}$. Each of the mobile phase solvents contained $1 \%$ of acetic acid, and the flow rate, wavelength and column temperature were set at $2.0 \mathrm{~mL} \mathrm{~min}{ }^{-1}, 280 \mathrm{~nm}$ and $28^{\circ} \mathrm{C}$, respectively.

\section{Procedure}

\section{Preparation of standard solutions}

As much as $0.125 \mathrm{~g}$ of each SPAs (PG, TBHQ, BHA and $\mathrm{BHT}$ ) were measured to prepare a stock solution (500 $\mathrm{mg} \mathrm{L}^{-1}$ ) in a $250 \mathrm{~mL}$ volumetric flask. $\mathrm{H}_{2} \mathrm{O} / \mathrm{ACN}$ in 1:9 (v/v) was used to dissolve the SPAs and was made up to the volume of $250 \mathrm{~mL}$. The flask was shaken in an ultrasonic bath for $10 \mathrm{~min}$ until a homogenous and clear solution was formed. A series of standard solutions $(25 \mathrm{~mL}$ each) with the concentrations of $1,5,10,50,100$ and $300 \mathrm{mg} \mathrm{L}^{-1}$ were prepared by diluting the stock solution with $\mathrm{H}_{2} \mathrm{O} / \mathrm{ACN}(1: 9, \mathrm{v} / \mathrm{v})$ and they were used to obtain the calibration curves. These standard solutions were stored at $4{ }^{\circ} \mathrm{C}$ prior to analyses.

\section{Sample extraction procedure}

A total of 83 food samples, comprising of 5 chewing gum, 5 chili sauce, 5 cereal-based snack food, 3 noodle, 7 potato snack, 3 cereal breakfast, 7 oat, 5 biscuit, 3 cookie, 5 coffee, 5 junk food, 5 seaweed, 5 nut, 5 chocolate, 5 apple juice, 5 orange juice and 5 blackcurrant juice were analyzed. All these food items were purchased from retails and supermarkets in Klang Valley region, Malaysia. All the solid food samples were accurately weighed $(10 \mathrm{~g})$ and ground into fine powder. The ground food samples were transferred into a $100 \mathrm{~mL}$ stoppered conical flask and extracted with $\mathrm{MeOH} / \mathrm{ACN}(50 \mathrm{~mL}) 1: 1(\mathrm{v} / \mathrm{v})$ in an ultrasonic bath for $15 \mathrm{~min}$. The food samples were vortexed for $15 \mathrm{sec}$, followed by centrifugation at $3500 \mathrm{rpm}$ for $10 \mathrm{~min}$. The clear upper layer was transferred into a glass tube and kept in a refrigerator at $4{ }^{\circ} \mathrm{C}$ for at least $2 \mathrm{~h}$. The bottom layer that contained food residues was discarded. After $2 \mathrm{~h}$, the upper layer was filtered through a membrane filter $(0.45 \mu \mathrm{m} \times 47 \mathrm{~mm})$. The filtrate was transferred into a HPLC vial and analyzed. For the chili sauce and fruit juice samples, $5 \mathrm{~mL}$ of each sample was mixed with $10 \mathrm{~mL}$ of $\mathrm{MeOH} / \mathrm{ACN}(1: 1 \mathrm{v} / \mathrm{v})$ and centrifuged for $10 \mathrm{~min}$ at $3500 \mathrm{rpm}$. The samples were kept in a refrigerator at $4{ }^{\circ} \mathrm{C}$ for $2 \mathrm{~h}$. Next, the top layer was filtered through a $0.2 \mu \mathrm{m}$ syringe filter into $2 \mathrm{~mL}$ HPLC vials and ready for HPLC analysis, while the bottom layer was discarded. Each food sample was analyzed in triplicate.

\section{- RESULTS AND DISCUSSION}

\section{HPLC Method Development and Optimization}

In order to obtain the best efficiency and resolution for a chromatography separation within the shortest time possible, the influence of certain important variables was studied. As the SPAs used in this study are phenolic antioxidants, the mobile phase used was either acidic or buffered. This was done in order to avoid ionization of the phenolic group(s) which may cause tailing and additional peaks due to ionized, unionized and neutral forms of the phenolic compounds. Mixture of acetonitrile and water with $1 \%$ acetic acid in gradient mode (compositions varied between 30 to $95 \%$ ) has been reported by Saad et al. [14] in the analyses of SPAs in cooking oils, margarines, butters and cheese samples. Mobile phase containing acetonitrile with $1 \%$ acetic acid and water with $1 \%$ acetic acid (compositions ranging from $30 \% \mathrm{ACN}$ to $100 \% \mathrm{ACN}$ ) has been studied by Razali et al. [15] to determine SPAs in palm oils. The gradient eluents containing two solutions: solution $\mathrm{A}$ (methanol with acetic acid, 95/5, v/v) and solution B (water with acetic acid, 95/5, v/v) (elution programme was varied from 50 to $85 \%$ of A) were used by Rafecas et al. [16] for the analyses of phenolic antioxidants in bakery products. The determination of SPAs using GCMS has been reported by Wang et al. [7] for the analyses of BHT in the resin-based dental sealants, Biparva et al. [1] in the analyses of fruit juice samples and Cacho et al. [9] in the analyses of BHT, BHA and TBHQ in edible oils. Since SPAs are are neither volatile nor semi-volatile phenolic compounds, therefore the HPLC method was chosen for our analyses. Modified HPLC methods by Saad et al. [14] and Razali et al. [15] were tested in our analyses to suit various food stuffs that have different matrices as compared to oil products. The same mobile phase combination i.e. ACN and water was used because of their overall lower viscosity and better separation efficiency as compared to methanol and water 
combination. The weak acid, acetic acid was used because it can prevent ionization of the hydroxyl groups of the phenolic antioxidants.

\section{Selection of Elution Method}

Isocratic elution was tried in the initial analysis. The amount of ACN with $1 \%$ acetic acid and water with $1 \%$ acetic acid varied between 30 and 70\%. However, poor separation efficiency, poor resolution and overlapping of peaks were observed in these isocratic analyses. Therefore, gradient eluents with ACN (with $1 \%$ acetic acid) and water (with $1 \%$ acetic acid) in ratios ranging from $30 \%$ ACN to $100 \%$ ACN were tested. Good separation efficiency and resolution were obtained with the following settings: $0 \mathrm{~min}, 40 \% \mathrm{ACN}, 60 \% \mathrm{H}_{2} \mathrm{O} ; 1 \mathrm{~min}, 50 \% \mathrm{ACN}$, $50 \% \mathrm{H}_{2} \mathrm{O} ; 2 \mathrm{~min}, 60 \% \mathrm{ACN}, 40 \% \mathrm{H}_{2} \mathrm{O} ; 3 \mathrm{~min}, 80 \% \mathrm{ACN}$, $20 \% \mathrm{H}_{2} \mathrm{O} ; 5$ min, $90 \%$ ACN, $10 \% \mathrm{H}_{2} \mathrm{O} ; 7-10 \mathrm{~min}, 100 \%$ ACN, $0 \% \mathrm{H}_{2} \mathrm{O}$; with the mobile phase flow rate of

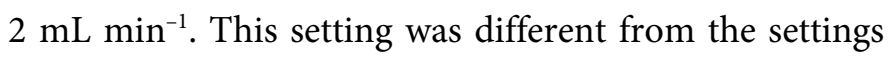
used by Razali et al. [15] (with a flow rate of $2 \mathrm{~mL} \mathrm{~min}^{-1}$ from $30 \%$ ACN with $1 \%$ acetic acid and $70 \%$ water with $1 \%$ acetic acid to $100 \%$ of ACN in 7 min and holding for $5 \mathrm{~min}$ at $100 \%$ of ACN; column: Supelco C18, $150 \mathrm{~mm} \times$ $4.0 \mathrm{~mm} \times 5 \mu \mathrm{m}$ ) and Saad et al. [14] (a gradient mode comprising $\mathrm{ACN}$ and water with $1 \%$ acetic acid which was increased from $30 \% \mathrm{ACN}$ to $95 \% \mathrm{ACN}$ within 5 min and continued to $100 \% \mathrm{ACN}$ in another 4 min with a flow rate of $1.5 \mathrm{~mL} \mathrm{~min}^{-1}$; column: LiChrospher C18, $250 \mathrm{~mm} \times 4.0$ $\mathrm{mm} \times 5 \mu \mathrm{m}$ ). In our analysis, complete separation was achieved in less than 8 min which is comparable to Saad et al. [14] and Razali et al. [15], with the separation time of 7.5 and $8 \mathrm{~min}$, respectively.

\section{Effect of Wavelengths}

The absorption wavelengths for individual phenolic antioxidants in their respective solvents as reported by some authors are as follows: PG, $275 \mathrm{~nm}$, methanol-water; BHA, $290 \mathrm{~nm}$, chloroform-methanol; BHT, $284 \mathrm{~nm}$, cyclohexane [17] and TBHQ, $292 \mathrm{~nm}$, methanol [18], respectively. In order to obtain maximum absorption bands in water and ACN mobile phase (both with $1 \%$ acetic acid) using the above mentioned gradient elution, six different wavelengths were chosen. The chosen wavelengths are 270, 275, 280, 285, 290 and $295 \mathrm{~nm}$ (increment of $5 \mathrm{~nm}$ for each successive wavelength). Maximum absorption bands were observed at wavelengths 280 and $285 \mathrm{~nm}$. Since better gaussian curves were observed at $280 \mathrm{~nm}$ compared to $285 \mathrm{~nm}$, therefore, $280 \mathrm{~nm}$ was chosen for the rest of the studies. As a compromise between retention time and sensitivity, flow rate of $2 \mathrm{~mL} \mathrm{~min}^{-1}$, column temperature of $28^{\circ} \mathrm{C}$ (as it is the same as ambient temperature) and injection volume of $10 \mu \mathrm{L}$ were adopted, and these conditions were used in all the experiments.

\section{Method Optimization of Extraction Method}

Extraction method plays an important role in removing interfering matrix component as well as to concentrate analytes of interest to enhance its sensitivity [19]. Various extraction methods have been used by different researchers to isolate antioxidants from food samples. These include liquid-liquid extraction [12], solid-phase extraction [20], cloud point micro-extraction [3], and liquid-phase microextraction [21]. Solid-phase extraction is popular due to its environment-friendly characteristic, as little amount of solvent is used [20]. However, solid-phase extraction method is relatively time consuming whereby it requires multiple-step of solvents clean-up. The cloud point micro-extraction and liquid-phase micro-extraction are greener methods due to the use of microliters of solvents in the extraction steps. However, these methods may result in the great loss of attainable sensitivity [9], possible formation of air bubbles and the extraction methods could be timeconsuming [1]. Among these methods, liquid-liquid extraction (LLE) is the most common method employed for pre-concentration and clean-up of SPAs due to its effectiveness and simplicity. Therefore, selection of appropriate solvent is of great importance. In LLE, various solvents have been used by different researchers for the extraction of SPAs in food stuffs and these include methanol [15], acetonitrile [2], 2-ethyl-1hexanol [1], acetonitrile with saturated hexane [19] and methanol/acetonitrile (1:1) [14]. Extraction of SPAs using methanol had been reported to show some unsatisfactory results especially for BHT [14]. In addition, another disadvantage of using methanol as 
extraction solvent is the high recoveries of $\mathrm{PG}$ and $\mathrm{TBHQ}$ probably due to the coextraction of interfering compounds such as lipids and proteins [22]. 2-ethyl-1hexanol is an organic solvent that is totally immiscible with water. Other organic solvents such as acetone may produce cloudiness in the solution when aqueous samples were to be analyzed [1]. The Korean Food Standards Code reported that the use of acetonitrile saturated with hexane gave good recoveries (89.6-98.3\%) for the extraction of oil samples [19]. However, this combination of solvents may not be suitable for the extraction of SPAs in aqueous samples due to the insolubility of hexane in water. Saad et al. [14] reported that the use of $\mathrm{MeOH} / \mathrm{ACN} 1: 1(\mathrm{v} / \mathrm{v})$ in a single step LLE procedure gave good recoveries (73.9$108.3 \%$ ) when extracting SPAs in cooking oils, bread spreads, and cheese samples. Perrin and Meyer [23] reported the use of different combinations of solvents (methanol; hexane/2-propanol, 1:1 v/v; ACN/2propanol/methanol, 2:1:1; ACN/2-propanol/ethanol, $2: 1: 1)$ for the extraction of SPAs in various dry food products (bouillons, gravies, dehydrated soups, dehydrated meat and dry pet food). However, the extraction methods are tedious because they involve the use of different combinations of solvents for different types of foods and SPAs. Considering the above factors, we used the extraction method proposed by Saad et al. [14], due to its good recovery and suitability for our scope of work that uses a 1:1 (v/v) ratio $\mathrm{MeOH} / \mathrm{ACN}$ for the extraction of SPAs in our analyses. Good recoveries (74.5-110.6\%) were obtained for the various food stuffs. For the fruit juice samples, the same solvent combination was used but with some modification, where the juice samples were mixed with the solvent mixture and homogenised with a shaker. The resulting solutions were then centrifuged and refrigerated overnight to discard any precipitate.

\section{Method Validation}

The presence of SPAs in the food samples were identified by matching the peak retention times with the values of the corresponding standards. The reliability of the chromatographic method in this study was validated by determining the linear range, repeatability and reproducibility, limits of detection (LOD) and quantitation (LOQ), and recovery. The linearity of the calibration curves was studied over the range of 1$300 \mathrm{mg} / \mathrm{L}$ for all the four SPAs and all the standards were analyzed in triplicate (Table 1). High correlation coefficients $\left(R^{2}: 0.9990-0.9997\right)$ were found for the four SPAs for the concentration ranges being studied, indicating good linearity between peak area and analyte concentration.

The limit of detection (LOD) for each SPAs was determined from the minimum concentration required to give a signal to noise ratio of three, while the LOQ were determined with a signal to noise ratio of 10 [14]. The LOD and LOQ values of the four SPAs ranged from 0.0197-0.6694 $\mathrm{mg} \mathrm{L}^{-1}$ and 0.0597-2.0287 $\mathrm{mg} \mathrm{L}^{-1}$, respectively (Table 1 ). These results agreed with results obtained by other authors [14,19]. The repeatability and reproducibility of the method were evaluated by calculating the relative standard deviation (RSD) of the areas for three consecutive injections of the SPAs standard solutions. The analyses were conducted on the same day and over seven days for intraday and interday repeatability, respectively. Good repeatability and reproducibility were

Table 1. Analytical characteristics of the HPLC method

\begin{tabular}{lclccccc}
\hline SPA & $\begin{array}{c}\text { Linear range } \\
(\mathrm{mg} / \mathrm{L})\end{array}$ & Regression equation & $\mathrm{R}^{2}$ & $\begin{array}{c}\text { Intraday (\% RSD }) \\
(\mathrm{n}=3)\end{array}$ & $\begin{array}{c}\text { Interday (\% RSD }) \\
(\mathrm{n}=3)\end{array}$ & $\begin{array}{c}\text { LOD } \\
(\mathrm{mg} / \mathrm{L})\end{array}$ & $\begin{array}{c}\text { LOQ } \\
(\mathrm{mg} / \mathrm{L})\end{array}$ \\
\hline PG & $1-300$ & $\mathrm{Y}=5.73 \mathrm{X}-4.759$ & 0.9997 & 0.15 & 0.84 & 0.0934 & 0.2831 \\
TBHQ & $1-300$ & $\mathrm{Y}=2.439 \mathrm{X}-1.202$ & 0.9996 & 0.19 & 0.61 & 0.0420 & 0.1272 \\
BHA & $1-300$ & $\mathrm{Y}=2.822 \mathrm{X}-2.176$ & 0.9994 & 0.12 & 0.63 & 0.6694 & 2.0287 \\
BHT & $1-300$ & $\mathrm{Y}=0.984 \mathrm{X}-0.210$ & 0.9990 & 0.73 & 0.78 & 0.0197 & 0.0597 \\
\hline
\end{tabular}

$\mathrm{X}$, concentration of amine $(\mathrm{mg} / \mathrm{L})$; Y, peak area of SPAs; $\mathrm{R}^{2}$, square of regression coefficient; LOD, limit of detection; LOQ, limit of quantification; RSD, relative standard deviation 
Table 2. Recoveries and RSD of SPAs when spiked to selected food samples

\begin{tabular}{|c|c|c|c|c|c|c|c|c|c|}
\hline \multirow{3}{*}{ SPA } & \multicolumn{9}{|c|}{ \% Recovery } \\
\hline & \multicolumn{3}{|c|}{$10 \mathrm{mg} / \mathrm{L}$} & \multicolumn{3}{|c|}{$50 \mathrm{mg} / \mathrm{L}$} & \multicolumn{3}{|c|}{$100 \mathrm{mg} / \mathrm{L}$} \\
\hline & $\begin{array}{l}\text { Potato } \\
\text { Snack }\end{array}$ & Oat & $\begin{array}{l}\text { Chewing } \\
\text { gum }\end{array}$ & $\begin{array}{l}\text { Potato } \\
\text { Snack }\end{array}$ & Oat & $\begin{array}{l}\text { Chewing } \\
\text { gum }\end{array}$ & $\begin{array}{l}\text { Potato } \\
\text { Snack }\end{array}$ & Oat & $\begin{array}{l}\text { Chewing } \\
\text { gum }\end{array}$ \\
\hline PG & $\begin{array}{l}105.25 \\
(0.32)\end{array}$ & $\begin{array}{l}86.87 \\
(2.14)\end{array}$ & $\begin{array}{l}113.84 \\
(0.26)\end{array}$ & $\begin{array}{l}97.3 \\
(0.6)\end{array}$ & $\begin{array}{l}85.4 \\
(0.4)\end{array}$ & $\begin{array}{l}97.27 \\
(0.68)\end{array}$ & $\begin{array}{l}117.7 \\
(0.6)\end{array}$ & $\begin{array}{l}105.4 \\
(0.2)\end{array}$ & $\begin{array}{l}103.12 \\
(0.66)\end{array}$ \\
\hline TBHQ & $\begin{array}{l}106.69 \\
(0.83)\end{array}$ & $\begin{array}{l}93.66 \\
(1.25)\end{array}$ & $\begin{array}{l}106.29 \\
(3.21)\end{array}$ & $\begin{array}{l}90.9 \\
(3.1)\end{array}$ & $\begin{array}{l}98.2 \\
(3.4)\end{array}$ & $\begin{array}{l}95.21 \\
(3.13)\end{array}$ & $\begin{array}{l}110.9 \\
(2.1)\end{array}$ & $\begin{array}{l}108.0 \\
(0.5)\end{array}$ & $\begin{array}{l}80.42 \\
(3.17)\end{array}$ \\
\hline BHA & $\begin{array}{l}119.00 \\
(0.15)\end{array}$ & $\begin{array}{l}102.61 \\
(3.11)\end{array}$ & $\begin{array}{l}105.53 \\
(0.84)\end{array}$ & $\begin{array}{l}95.4 \\
(0.8)\end{array}$ & $\begin{array}{l}100.3 \\
(1.6)\end{array}$ & $\begin{array}{l}103.20 \\
(0.88)\end{array}$ & $\begin{array}{l}85.4 \\
(3.2)\end{array}$ & $\begin{array}{l}87.8 \\
(0.7)\end{array}$ & $\begin{array}{l}103.52 \\
(0.85)\end{array}$ \\
\hline BHT & $\begin{array}{l}108.69 \\
(2.21)\end{array}$ & $\begin{array}{l}112.13 \\
(0.66)\end{array}$ & $\begin{array}{l}89.70 \\
(1.54)\end{array}$ & $\begin{array}{l}103.1 \\
(1.5)\end{array}$ & $\begin{array}{l}102.1 \\
(1.1)\end{array}$ & $\begin{array}{l}117.77 \\
(1.52)\end{array}$ & $\begin{array}{l}93.8 \\
(2.1)\end{array}$ & $\begin{array}{l}109.1 \\
(1.2)\end{array}$ & $\begin{array}{l}110.08 \\
(1.65)\end{array}$ \\
\hline
\end{tabular}

Value in brackets denote relative standard deviation (RSD) $(\mathrm{n}=3)$

obtained with RSD values ranging from 0.12 to $0.73 \%$ and from 0.61 to $0.84 \%$, respectively (Table 1 ). The recovery studies were conducted by spiking three different concentrations $\left(10,50,100 \mathrm{mg} \mathrm{L}^{-1}\right)$ of the standard solutions containing the SPAs to three of the food samples. The mean values for the recovery analysis ranged from $86.9 \pm 2.1 \%$ to $117.7 \pm 0.6 \%$ for PG, $80.4 \pm 3.2 \%$ to $110.9 \pm 2.1 \%$ for TBHQ, $85.4 \pm 3.2 \%$ to $119.0 \pm 0.2 \%$ for BHA, and $89.7 \pm$ $1.5 \%$ to $117.8 \pm 1.5 \%$ for BHT (Table 2). The results were satisfactory and in agreement with previous findings $[9,19]$.

\section{Analysis of Food Samples}

The optimised and validated method was applied for the analysis of 83 food samples consisting of different varieties and brands ( 5 chewing gum, 5 chili sauce, 5 cereal-based snack foods, 3 noodle, 7 potato snacks, 3 cereal breakfast, 7 oat, 5 biscuit, 3 cookie, 5 coffee, 5 junk foods, 5 seaweed, 5 nut, 5 chocolate, 5 apple juice, 5 orange juice and 5 blackcurrant juice). Quantification of the SPAs in the food samples was based on the external standard method using calibration curves fitted by linear regression analysis. Out of 83 food samples, 29 gave positive SPAs values and the results are summarized in Table 3. Fig. 1(a) and 1(c) show typical chromatograms of potato snack and chewing gum, respectively. They were spiked with the four standard SPAs $\left(100 \mathrm{mg} \mathrm{kg}^{-1}\right)$ (Fig. $1(\mathrm{~b})$ and $1(\mathrm{~d})$ ) for further identification and confirmation. All the four SPAs were well resolved and completely eluted in less than 8 min.

All the four SPAs were found in the food samples, and they were added either singly or in combination of two or three. From the food samples analyzed, PG was the most dominant SPA, present at $20.5 \%(17 / 83)$ in the food samples, followed by BHA (12.1\%, 10/83), TBHQ and BHT (both at $3.6 \%, 3 / 83$ ). The concentration ranges were found to be $1.07-23.72 \mathrm{mg} \mathrm{kg}^{-1}$ for PG, $1.59-31.17$ $\mathrm{mg} \mathrm{kg}{ }^{-1}$ for TBHQ, 2.74-18.47 $\mathrm{mg} \mathrm{kg}^{-1}$ for BHA (the value of $1.83 \mathrm{mg} \mathrm{kg}^{-1}$ is below the LOQ level which should not be quantitated), and $7.78-72.72 \mathrm{mg} \mathrm{kg}^{-1}$ for BHT. None of these samples exceeded the legal limits of $100 \mathrm{mg} \mathrm{kg}^{-1}$ for any single SPA or $200 \mathrm{mg} \mathrm{kg}^{-1}$ for any combinations [1] or the legal limit of $200 \mathrm{mg} \mathrm{kg}^{-1}$ for total SPAs as specified in the Food Act (1983) [5] and Food Regulations (1985) [4] of Malaysia.

Comparing the total SPAs levels of the 83 food samples analyzed in this study (Table 3), on average 'chewing gum 2' showed the highest SPAs content (72.72 $\left.\pm 0.76 \mathrm{mg} \mathrm{kg}^{-1}\right)$, followed by 'cookie $18^{\prime}$ ( $51.86 \pm 1.77 \mathrm{mg}$ $\left.\mathrm{kg}^{-1}\right)$, 'chewing gum 1' (51.39 $\left.\pm 0.89 \mathrm{mg} \mathrm{kg}^{-1}\right)$ and 'oat 13' $\left(23.72 \pm 0.12 \mathrm{mg} \mathrm{kg}^{-1}\right)$. The rest of the food samples contained varying total SPAs of less than $20 \mathrm{mg} \mathrm{kg}^{-1}$. With reference to individual SPA, the highest PG level was found in 'oat 13' $\left(23.72 \pm 0.12 \mathrm{mg} \mathrm{kg}^{-1}\right)$, followed by 'cookie 19' and 'oat 11' with PG values of $19.74 \pm 1.25 \mathrm{mg}$ $\mathrm{kg}^{-1}$ and $15.27 \pm 0.70 \mathrm{mg} \mathrm{kg}^{-1}$, respectively. The rest of the food samples showed PG levels less than $15 \mathrm{mg} \mathrm{kg}^{-1}$. 


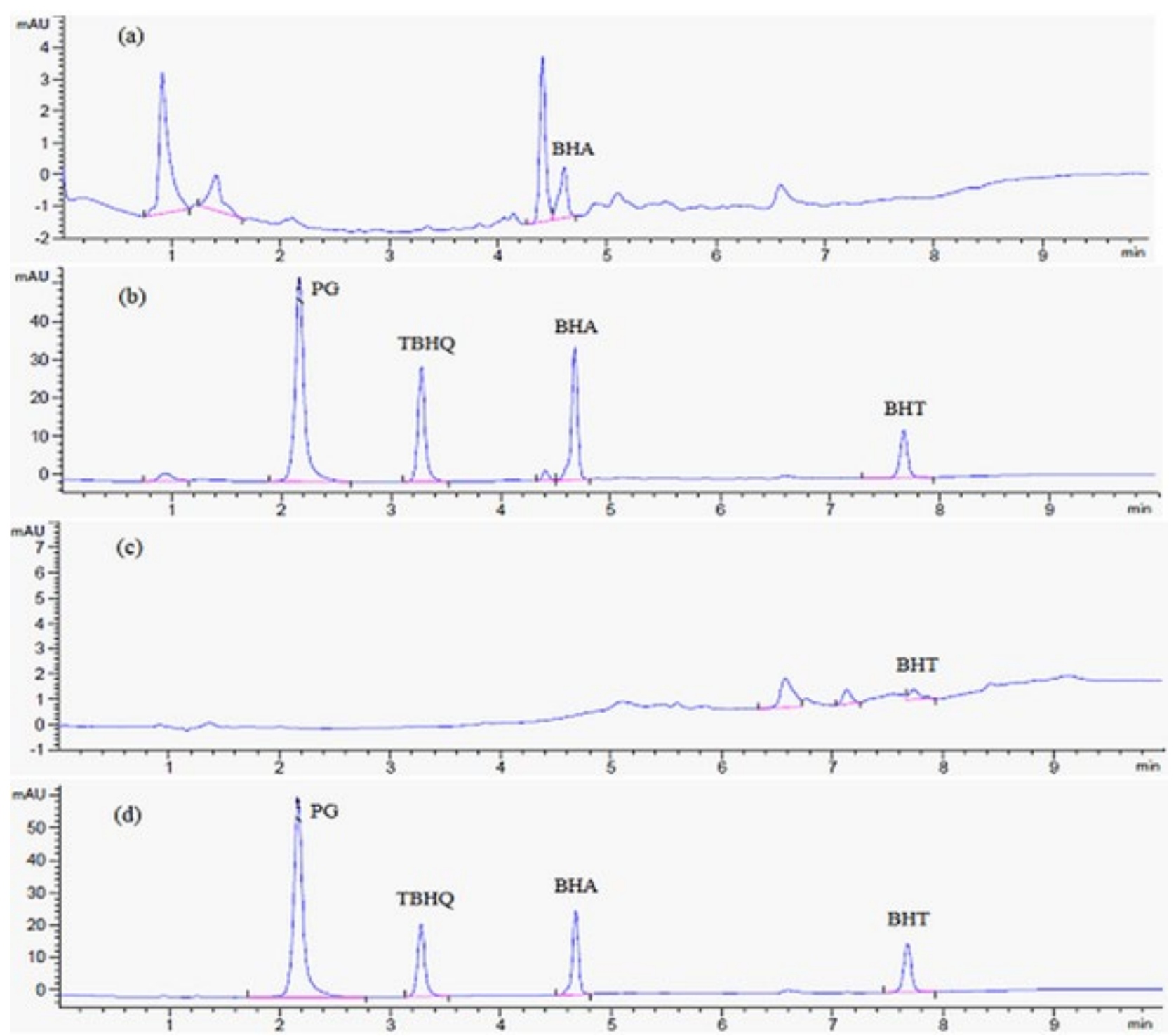

Fig 1. Typical HPLC chromatograms obtained from: (a) potato snack sample; (b) potato snack spiked with standard mixture of SPAs (100 $\mathrm{mg} \mathrm{kg}^{-1}$ ); (c) chewing gum sample, (d) chewing gum sample spiked with standard mixture of SPAs $\left(100 \mathrm{mg} \mathrm{kg}^{-1}\right)$

For TBHQ, 'cookie 18 ' showed the highest value (31.17 \pm $0.47 \mathrm{mg} \mathrm{kg}^{-1}$ ) and the rest of the samples contained TBHQ of below $5 \mathrm{mg} \mathrm{kg}^{-1}$. None of the food samples contained BHA more than $20 \mathrm{mg} \mathrm{kg}^{-1}$ and the highest was found in 'cookie 18 ' (18.47 $\left.\pm 1.25 \mathrm{mg} \mathrm{kg}^{-1}\right)$, followed by 'seaweed $25^{\prime}$ $\left(16.81 \pm 0.61 \mathrm{mg} \mathrm{kg}^{-1}\right)$ and 'nut 27 ' (12.14 $\left.\pm 0.17 \mathrm{mg} \mathrm{kg}^{-1}\right)$. BHT was only found in 'chewing gum' samples, with the highest value of $72.72 \pm 0.76 \mathrm{mg} \mathrm{kg}^{-1}$ ('chewing gum 2') followed by $51.39 \pm 0.89 \mathrm{mg} \mathrm{kg}^{-1}$ ('chewing gum 1') and $7.78 \pm 1.03 \mathrm{mg} \mathrm{kg}^{-1}$ ('chewing gum 3'). For chewing gum (nos. 1, 2 and 3) and biscuit (no. 23) samples, the manufacturers declared the presence of BHT and TBHQ as synthetic antioxidants in their foods, respectively. Their labelling information is consistent with our findings. However, the amount of BHT and TBHQ added in the respective foods is not stated. As for the other types of food, no labelling information regarding SPAs added, is given (Table 3). The use of single PG, single TBHQ, single BHA and single BHT were found in chocolate (PG), seaweed (BHA), junk food (BHA), oat (PG), potato snack (BHA), noodle (BHA), and chewing gum (BHT) as shown in Fig. 2. The use of combination 
Table 3. Levels of SPAs found in SPA-positive food items $(n=3)$

\begin{tabular}{|c|c|c|c|c|c|c|c|c|c|}
\hline \multirow{2}{*}{ No. } & \multirow{2}{*}{ Sample } & \multirow{2}{*}{ Origin } & \multicolumn{5}{|c|}{ SPAs $\left(\mathrm{mg} \mathrm{kg}^{-1}\right)$} & \multirow{2}{*}{ Labelling } & \multirow{2}{*}{ Cluster } \\
\hline & & & PG & TBHQ & BHA & BHT & Total & & \\
\hline 1 & Chewing gum 1 & Philippines & ND & ND & ND & $51.39 \pm 0.89$ & $51.39 \pm 0.89$ & $\mathrm{BHT}^{\mathrm{a}}$ & 3 \\
\hline 2 & Chewing gum 2 & Philippines & ND & ND & ND & $72.72 \pm 0.76$ & $72.72 \pm 0.76$ & $\mathrm{BHT}^{\mathrm{a}}$ & 3 \\
\hline 3 & Chewing gum 3 & Vietnam & ND & ND & ND & $7.78 \pm 1.03$ & $7.78 \pm 1.03$ & $\mathrm{BHT}^{\mathrm{a}}$ & 5 \\
\hline 4 & Noodle & Malaysia & ND & ND & $4.08 \pm 0.18$ & ND & $4.08 \pm 0.18$ & - & 5 \\
\hline 5 & Potato snack 1 & Malaysia & ND & ND & $1.61 \pm 0.13$ & ND & $1.61 \pm 0.13$ & - & 5 \\
\hline 6 & Potato snack 2 & Malaysia & ND & ND & $3.82 \pm 0.64$ & ND & $3.82 \pm 0.64$ & - & 5 \\
\hline 7 & Potato snack 3 & Malaysia & ND & ND & $5.71 \pm 0.80$ & ND & $5.71 \pm 0.80$ & - & 5 \\
\hline 8 & Cereal breakfast 1 & Malaysia & ND & $3.07 \pm 0.12$ & ND & ND & $3.07 \pm 0.12$ & - & 5 \\
\hline 9 & Cereal breakfast 2 & Malaysia & $12.45 \pm 0.44$ & ND & ND & ND & $12.45 \pm 0.44$ & - & 4 \\
\hline 10 & Cereal breakfast 3 & Malaysia & $1.18 \pm 0.10$ & ND & ND & ND & $1.18 \pm 0.10$ & - & 5 \\
\hline 11 & Oat 1 & United States & $15.27 \pm 0.70$ & ND & ND & ND & $15.27 \pm 0.70$ & - & 4 \\
\hline 12 & Oat 2 & Australia & $2.08 \pm 0.06$ & ND & ND & ND & $2.08 \pm 0.06$ & - & 5 \\
\hline 13 & Oat 3 & Malaysia & $23.72 \pm 0.12$ & ND & ND & ND & $23.72 \pm 0.12$ & - & 4 \\
\hline 14 & Oat 4 & Australia & $9.52 \pm 0.18$ & ND & ND & ND & $9.52 \pm 0.18$ & - & 4 \\
\hline 15 & Oat 5 & Australia & $1.81 \pm 0.04$ & ND & ND & ND & $1.81 \pm 0.04$ & - & 5 \\
\hline 16 & Oat 6 & Australia & $2.46 \pm 0.06$ & ND & ND & ND & $2.46 \pm 0.06$ & - & 5 \\
\hline 17 & Oat 7 & United states & $2.19 \pm 0.03$ & ND & ND & ND & $2.19 \pm 0.03$ & - & 5 \\
\hline 18 & Cookie 1 & Malaysia & $2.2 \pm 0.05$ & $31.17 \pm 0.47$ & $18.47 \pm 1.25$ & ND & $51.86 \pm 1.77$ & - & 2 \\
\hline 19 & Cookie 2 & Malaysia & $19.74 \pm 1.25$ & ND & $2.74 \pm 0.04$ & ND & $19.74 \pm 1.29$ & - & 4 \\
\hline 20 & Cookie 3 & Malaysia & $13.0 \pm 0.49$ & ND & ND & ND & $13.0 \pm 0.49$ & - & 4 \\
\hline 21 & Biscuit 1 & Malaysia & ND & ND & $1.83^{\star} \pm 0.05$ & ND & $1.83^{\star} \pm 0.05$ & - & 5 \\
\hline 22 & Biscuit 2 & Malaysia & $1.07 \pm 0.21$ & ND & ND & ND & $1.07 \pm 0.21$ & - & 5 \\
\hline 23 & Biscuit 3 & Indonesia & $4.88 \pm 0.55$ & $1.59 \pm 0.23$ & ND & ND & $6.47 \pm 0.78$ & $\mathrm{TBHQ}^{\mathrm{a}}$ & 5 \\
\hline 24 & Junk food & Malaysia & ND & ND & $6.14 \pm 0.17$ & ND & $6.14 \pm 0.17$ & - & 5 \\
\hline 25 & Seaweed & Korea & ND & ND & $16.81 \pm 0.61$ & ND & $16.81 \pm 0.61$ & - & 1 \\
\hline 26 & Nut 1 & Malaysia & $13.32 \pm 1.23$ & ND & ND & ND & $13.32 \pm 1.23$ & - & 4 \\
\hline 27 & Nut 2 & Malaysia & ND & ND & $12.14 \pm 0.17$ & ND & $12.14 \pm 0.17$ & - & 1 \\
\hline 28 & Chocolate 1 & United Kingdom & $2.60 \pm 0.71$ & ND & ND & ND & $2.60 \pm 0.71$ & - & 5 \\
\hline 29 & Chocolate 2 & United States & $2.64 \pm 0.10$ & ND & ND & ND & $2.64 \pm 0.10$ & - & 5 \\
\hline
\end{tabular}

ND - not detected; * below LOQ; a, the concentration level of SPA is not stated; - the presence of antioxidant is not stated in the nutritional labelling

of two or three SPAs were found in cereal breakfast (PG and TBHQ), cookie (PG, TBHQ and BHA), biscuit (PG, TBHQ and BHA) and nut (PG and BHA) (Fig. 2).

PG has been found in food products such as vegetable oil [24], mushroom cream [24], bouillon [23], gravy [23], pre-cooked spaghetti [25] and perfume essence [3]. It was either added as single SPA or in combination of two or three SPAs. High levels of PG as a single SPA had been found in the vegetable oil (103 $\left.\mathrm{mg} \mathrm{kg}^{-1}\right)$ and mushroom cream $\left(2170 \mathrm{mg} \mathrm{kg}^{-1}\right)$ analyzed by Guan et al. [24] (Shanghai, China) and they have violated the legal limits of $100 \mathrm{mg} \mathrm{kg}^{-1}$ for a single SPA. BHA as single SPA was also encountered in different types of beef bouillon (n.d. to $8.6 \mathrm{mg} \mathrm{kg}^{-1}$ ), chicken bouillon (n.d. to $8.8 \mathrm{mg} \mathrm{kg}^{-1}$ ) and bouillon cubes (average, $4.6 \mathrm{mg} \mathrm{kg}^{-1}$ ) analyzed by Perrin and Meyer [23] (all samples were obtained from Switzerland), and liver pates samples obtained from a Portuguese retail market (from n.d. to $95.7 \mathrm{mg} \mathrm{kg}^{-1}$ ) analyzed by Pinho et al. [26]. On the other hand, Rafecas et al. [16] reported the use of BHA either added singly or in combination with BHT in bakery products, which included doughnuts, biscuits and various types of cake which were obtained in Spain. The concentrations found ranged from 3.9 to $10.7 \mathrm{mg} \mathrm{kg}^{-1}$ for BHA and from 3.0 to $17.0 \mathrm{mg} \mathrm{kg}^{-1}$ for BHT.

Biparva et al. [1] also reported the use of BHA and BHT in the fruit juice samples obtained from supermarkets located in Babolsar, Iran. The concentrations 


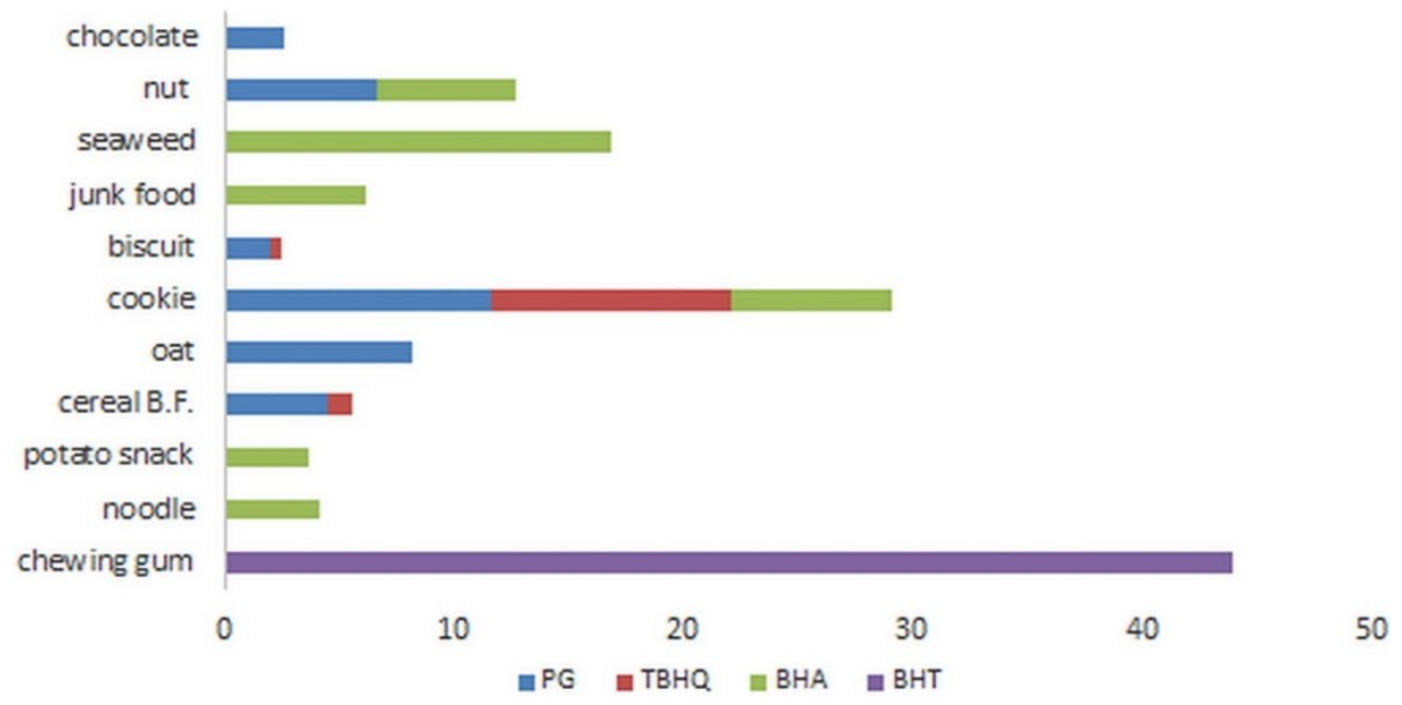

Fig 2. Mean values $\left(\mathrm{mg} \mathrm{kg}^{-1}\right)$ of SPAs in various food stuffs

\section{Final Cluster Centers}

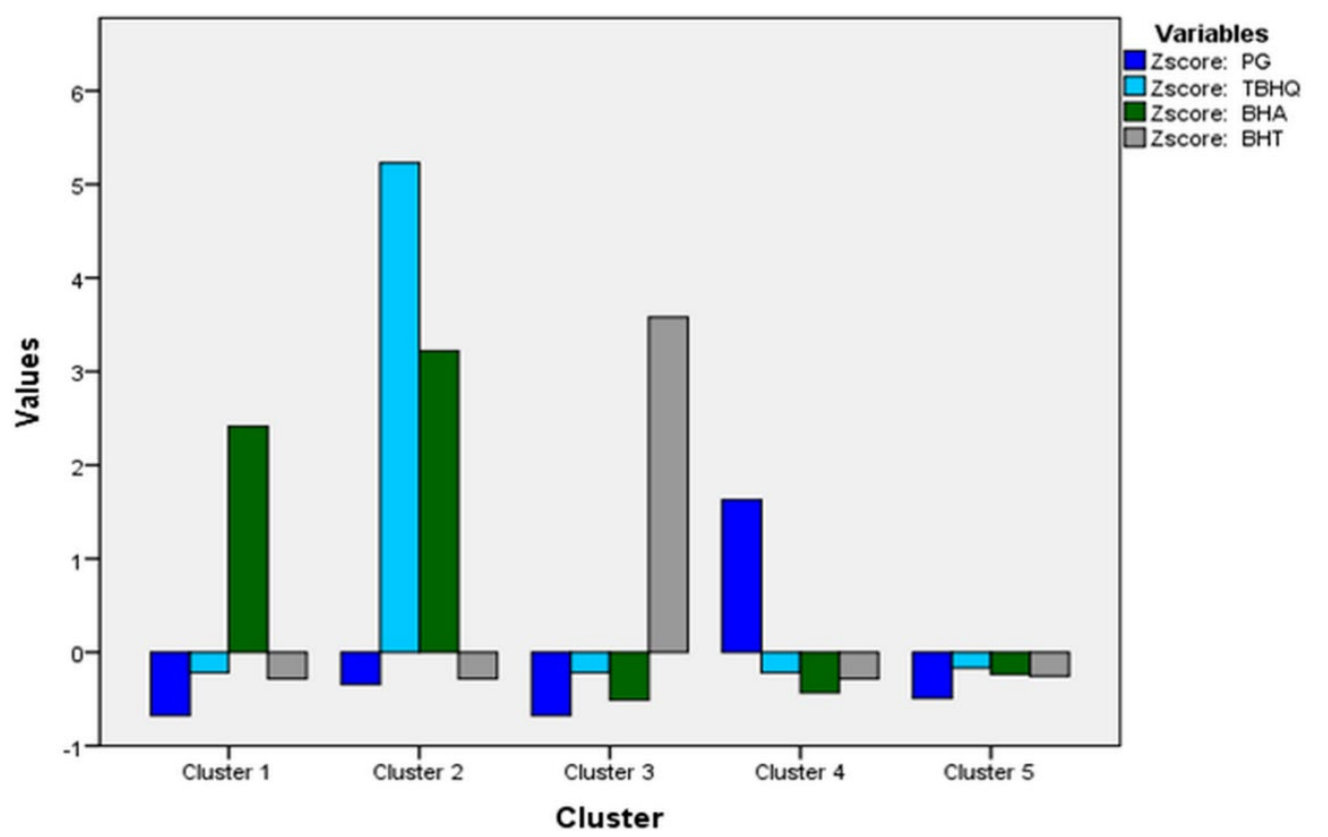

Fig 3. The 5-cluster system obtained from K-Means analysis in SPSS for the 29 food samples

found ranged from n.d. to $539 \mu \mathrm{g} \mathrm{L}^{-1}$ and from n.d. to $320 \mu \mathrm{g} \mathrm{L}{ }^{-1}$ for BHA and BHT, respectively. BHA and BHT were found to be added in the fruit juice samples either not at all, single BHT or combination of both. None of the samples contained total SPAs levels that exceeded the legal limits. On the other hand, in our case, none of the SPAs were detected in the fruit juice samples analyzed. Most probably, other antioxidants or preservatives were added besides SPAs. For example, Onwordi et al. [27] reported the presence of benzoic acid (168 to $799 \mathrm{mg} \mathrm{L}^{-1}$ ), sulphur (IV) oxide (n.d. to $13.6 \mathrm{mg} \mathrm{L}^{-1}$ ) and sorbic acid (74 to $109 \mathrm{mg} \mathrm{L}^{-1}$ ) in the fruit juices obtained from Lagos, Nigeria. Amirpour et al. [28] reported the presence of sodium benzoate (n.d. to $288.5 \mathrm{mg} \mathrm{kg}^{-1}$ ) or potassium benzoate (n.d. to $284.3 \mathrm{mg} \mathrm{kg}^{-1}$ ) in the fruit juices purchased from the supermarkets in Sari, Iran. All these results may explain the absence of SPAs in the fruit juice samples analyzed by us. 


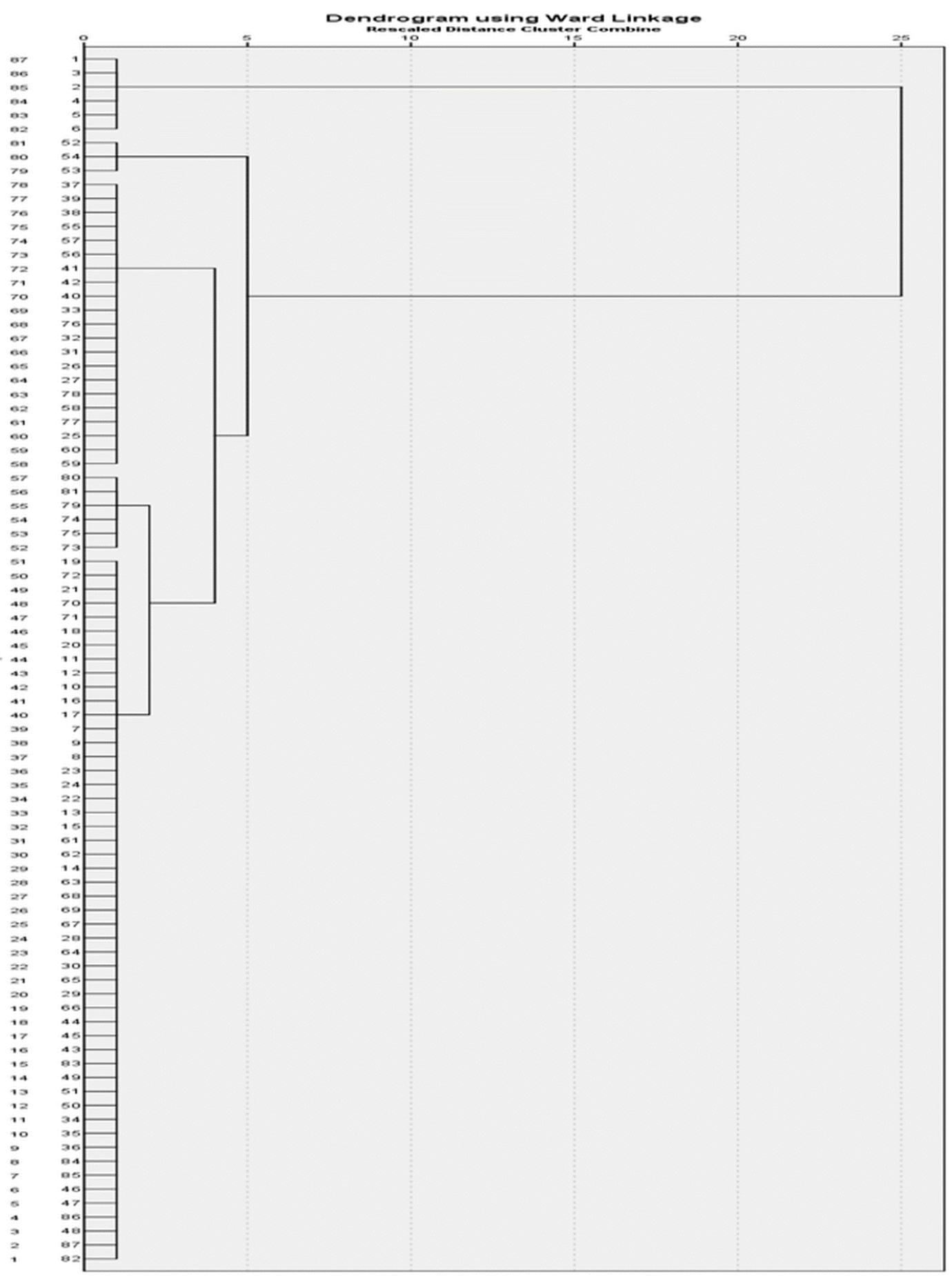

Fig 4. The dendrogram obtained from the Hierarchical analysis in SPSS for the 29 food samples. The numbers represent the food samples as in Table 3

In order to have a better understanding about the variation of SPAs added to each food sample, cluster analysis was carried out on the data of SPAs quantified from the 29 food samples. A Boxplot analysis was carried out prior to the cluster analysis. It was found that fivecluster is the best grouping system for this study because it produces minimum outlier (i. e. minimum number of rejection cases). Therefore, the 5-cluster system was 
chosen for the cluster analysis. Fig. 3 shows the 5 -cluster system obtained from the SPSS K-means analysis. This cluster method is based on the minimum distance of each food sample type to each fixed cluster centre. All variables were standardized previously. The results show that two food samples, namely seaweed (sample no. 25) and nut (sample no. 27) are categorized as cluster 1 (Table 3, last column). One food sample (cookie, sample no. 18) is categorized as cluster 2. Two food samples (chewing gums 1 and 2) as cluster 3 . Seven food samples (cereal breakfast no. 9 , oat no. 11,13 and 14 , cookie no. 19 and 20, and nut no. 26) are categorized as cluster 4 . While the remaining 17 food samples (chewing gum no. 3 , noodle no. 4 , potato snack no. 5, 6 and 7, cereal breakfast no. 8 and 10, oat no. $12,15,16$ and 17, biscuit no. 21, 22 and 23, junk food no. 24, and chocolate no. 28 and 29) are categorized as cluster 5. Referring to the one-way analysis of variance (ANOVA), significant differences between clusters were observed for all the 4 SPAs (PG, TBHQ, BHA and BHT) levels in different types of food. The results suggest that there are differences in the levels of SPAs according to the 5-cluster of food samples. The cluster analysis was further confirmed by using the Hierarchical cluster analysis where the dendrogram obtained (Fig. 4) indicates similar 5-cluster system for the food samples in this study.

\section{- CONCLUSION}

The proposed method shows good linearity, resolution, precision and recoveries. The developed method was suitable to be used for the analyses of various food stuffs that were of different matrices. The present study shows that all the four SPAs were found in various foods; they are either added as single SPA or in combination of two or three. None of the foods contained SPAs levels that exceeded the legal limits of $100 \mathrm{mg} \mathrm{kg}^{-} 1$ for single SPA or $200 \mathrm{mg} \mathrm{kg}^{-1}$ for total SPAs of any combinations as specified in the Food Act 1983 [5] and Food Regulations 1985 [4] of Malaysia. The analytical determination of SPAs in foods should be a continuous activity to ensure the safety and quality of food consumed. Moreover, modification or improvement of the analytical methods is necessary to ensure the accuracy and reliability of the existing methods for SPAs monitoring in the realworld food products.

\section{- ACKNOWLEDGMENTS}

We thank the Faculty of Applied Sciences of Tunku Abdul Rahman University College for its financial support.

\section{- REFERENCES}

[1] Biparva, P., Ehsani, M., and Hadjmohammadi, M.R., 2012, Dispersive liquid-liquid micro extraction using extraction solvents lighter than water combined with high performance liquid chromatography for determination of synthetic antioxidants in fruit juice samples, J. Food Compos. Anal., 27 (1), 87-94.

[2] Hajimahmoodi, M., Moghaddam, G., Hatefi, M., Khanavi, M., Sadeghi, N., Poureini, M., Oveisi, M.R., and Jannat, B., 2015, Gas chromatographic determination of synthetic antioxidants in liquid frying oil samples, Int. J. Dev. Res., 5 (2), 3489-3495.

[3] Li, X.L., Meng, D.L., Zhao, J., and Yang, Y.L., 2014, Determination of synthetic antioxidants in essence perfume by high performance liquid chromatography with vortex-assisted, cloud-point extraction using AEO-9, Chin. Chem. Lett., 25 (8), 1198-1202.

[4] Laws of Malaysia, Food Regulations 1985, http://myco2.com.my/phocadownloadpap/GovtAc tRegulation/Malaysia\%20Food\%20Regulation\%20 1985.pdf, accessed on September 30, 2018.

[5] Laws of Malaysia, Food Act 1983, https://www. kcc ci.org.my/attachments/article/1878/Draf\%20Warta \%20Peraturan-Peraturan\%20Makanan\%201985\%2 0(English)\%20190813.pdf, accessed on September 30, 2018.

[6] Yu, R., Mandlekar, S., and Kong, A.N.T., 2000, Molecular mechanisms of butylated hydroxyla nisole-induced toxicity: Induction of apoptosis through direct release of cytochrome $c, \mathrm{Mol}$. Pharmacol., 58 (2), 431-437.

[7] Wang, W., Kannan, P., Xue, J., and Kannan, K., 2016, Synthetic phenolic antioxidants, including 
butylated hydroxytoluene (BHT), in resin-based dental sealants, Environ. Res., 151, 339-343.

[8] Laningan, R.S., and Yamarik, T.A., 2002, Final report on the safety assessment of BHT, Int. J. Toxicol., 21 (Suppl. 2), 19-94.

[9] Cacho, J.I., Campillo, N., Viñas, P., and HernándezCórdoba, M., 2016, Determination of synthetic antioxidants in edible oils using microvial insert large volume injection gas-chromatography, Food Chem., 200, 249-254.

[10] Xiu-Qin, L., Chao, J., Yan-Yan, S., Min-Li, Y., and Xiao-Gang, C., 2009, Analysis of synthetic antioxidants and preservatives in edible vegetable oil by HPLC/ TOF-MS, Food Chem., 113 (2), 692-700.

[11] González, M., Gallego, M., and Valcárcel, M., 1999, Gas chromatographic flow method for the preconcentration and simultaneous determination of antioxidant and preservative additives in fatty foods, J. Chromatogr. A, 848 (1-2), 529-536.

[12] Guo, L., Xie, M.Y., Yan, A.P., Wan, Y.Q., and Wu, Y.M., 2006, Simultaneous determination for five synthetic antioxidants in edible oil by GC-MS, Anal. Bioanal. Chem., 386 (6), 1881-1887.

[13] Jaworska, M., Szulińska, Z., and Wilk, M., 2005, Application of a capillary electrophoresis method for simultaneous determination of preservatives in pharmaceutical formulations, J. Sep. Sci., 28 (2), 137143.

[14] Saad, B., Sing, Y.Y., Nawi, M.A., Hashim, N.H., Ali, A.S.M., Saleh, M.I., Sulaiman S.F., Md Talib, K., and Ahmad, K., 2007, Determination of synthetic phenolic antioxidants in food items using reversed-phase HPLC, Food Chem., 105 (1), 389-394.

[15] Razali, I., Norhaya, H., and Nor Asimah, A.S., 1997, Determination of antioxidants in palm oil products by high performance liquid chromatography, Elaeis, 9 (1), 25-33.

[16] Rafecas, M., Guardiola, F., Illera, M., Codony, R., and Boatella, J., 1998, Liquid chromatographic determination of phenolic antioxidants in bakery products, J. Chromatogr. A, 822 (2), 305-309.
[17] Nollet, L.M.L., 2004, Handbook of Food Analysis: Residues and Other Food Component Analysis, $2^{\text {nd }}$ Ed., Marcel Dekker, Inc., New York, U.S.A.

[18] Li, J., Bi, Y., Liu, W., and Sun, S., 2015, Simultaneous analysis of tertiary butylhydro quinone and 2-tert-Butyl-1,4-benzoquinone in edible oils by normal-phase high-performance liquid chromatography, J. Agric. Food. Chem., 63 (38), 8584-8591.

[19] Kim, J.M., Choi, S.H., Shin, G.H., Lee, J.H., Kang, S.R., Lee, K.Y., Lim, H.S., Kang, T.S., and Lee, O.H., 2016, Method validation and measurement uncertainty for the simultaneous determination of synthetic phenolic antioxidants in edible oils commonly consumed in Korea, Food Chem., 213, 19-25.

[20] Shui, G., and Leong, L.P., 2004, Analysis of polyphenolic antioxidants in star fruit using liquid chromatography and mass spectrometry, $J$. Chromatogr. A, 1022 (1-2), 67-75.

[21] Jeannot, M.A., and Cantwell, F.F., 1996, Solvent microextraction into a single drop, Anal. Chem., 68 (13), 2236-2240.

[22] Page, B.D., and Charbonneau, C.F., 1989, Liquid chromatographic determination of seven anti oxidants in dry foods, J. Assoc. Off. Anal. Chem., 72 (2), 259-265.

[23] Perrin, C., and Meyer, L., 2002, Quantification of synthetic phenolic antioxidants in dry foods by reversed-phase HPLC with photodiode array detection, Food Chem., 77 (1), 93-100.

[24] Guan, Y., Chu, Q., Fu, L., Wu, T., and Ye, J., 2006, Determination of phenolic antioxidants by micellar electrokinetic capillary chromatography with electrochemical detection, Food Chem., 94 (1), 157162.

[25] Mateos, R., Vera, S., Díez-Pascual, A.M., and San Andrés, M.P., 2017, Graphene solid phase extraction (SPE) of synthetic antioxidants in complex food matrices, J. Food Compos. Anal., 62, 223-230. 
[26] Pinho, O., Ferreira, I.M.P.L.V.O. Oliveira, M.B.P.P., and Ferreira, M.A., 2000, Quantification of synthetic antioxidants in liver pâstés, Food Chem., 68 (3), 353357.

[27] Onwordi, C.T., Olanrewaju A.J., Wusu A.D., and Oguntade, B.K., 2017, Levels of benzoic acid, sulphur (IV) oxide and sorbic acid in carbonated drinks sold in Lagos, Nigeria, Am. J. Food Sci. Technol., 5 (2), 38-44.

[28] Amirpour, M., Arman, A., Yolmeh, A., Azam, M.A., and Moradi-Khatoonabadi, Z., 2015, Sodium benzoate and potassium sorbate preservatives in food stuffs in Iran, Food Addit. Contam. Part B Surveill., 8 (2), 142-148. 